Original Research Article

\title{
Retrospective analysis of adverse drug reactions reported at ADR monitoring centre under PvPI in a tertiary care hospital
}

\author{
Manodeep Sen ${ }^{1}$ Arpita Singh ${ }^{2 *}$, Mukul Misra ${ }^{3}$
}

${ }^{1}$ Department of Microbiology, ${ }^{2}$ Department of Pharmacology, ${ }^{3}$ Department of Cardiology, Dr. Ram Manohar Lohia Institute of Medical Sciences, Lucknow, Uttar Pradesh, India

Received: 05 December 2017 Accepted: 28 December 2017

\section{*Correspondence to: \\ Dr. Arpita Singh, \\ Email: drarpitasingh21@ \\ gmail.com}

Copyright: (C) the author(s), publisher and licensee Medip Academy. This is an openaccess article distributed under the terms of the Creative Commons Attribution NonCommercial License, which permits unrestricted noncommercial use, distribution, and reproduction in any medium, provided the original work is properly cited.

\begin{abstract}
Background: Adverse drug reactions (ADRs) are a major cause of morbidity and mortality in hospitals and pose great economic burden on the health care system. This study was conducted with the aim of creating awareness and developing a culture for proper communication and reporting of ADRs among health care professionals.

Methods: This study is a retrospective analysis of total 60 reported ADRs from AMC at a tertiary care hospital during a period of 14 months from March 2015 to April 2016. These ADRs were analysed for the pattern and type of reactions, body systems involved, causative drugs, and severity of reaction, their outcome, management and causality assessment.

Results: Patients in the age groups of 41-50 years were most commonly involved with slight male preponderance. Skin reactions like rashes and itching were the most commonly observed ADR. The most common causative drugs for ADR were antimicrobial agents; IV route was the most common route responsible. Majority of ADRs belonged to type B, were non serious and moderate in severity. Most of the patients recovered. On causality assessment scale, most of the ADRs were found to be probable with the causative drugs.

Conclusions: Most of the ADRs were treatable by early and appropriate management. The major limitation was under-reporting of ADRs which can be overcome by creating awareness and enhancing the culture of ADR monitoring and reporting among health care professionals for safe use of drugs.
\end{abstract}

Keywords: Adverse drug reactions, AMC, Causality assessment, Pharmacovigilance

\section{INTRODUCTION}

According to latest WHO definition, ADR is "a harmful effect suspected to be caused by a drug". ${ }^{1}$ The morbidity and mortality associated with ADRs have a great impact on health of the society and poses great economic burden on the health care system of the county but the major concern is that the reporting of ADRs is considerably less due to lack of awareness and improper communication. So spontaneous reporting of ADR is very important for future health prospects of the society. Pharmacovigilance helps in early detection of ADRs, identification of risk factors and understanding the mechanisms underlying the ADR.
Pharmacovigilance is defined as, "The science and activities relating to the detection, assessment, understanding and prevention of adverse effects or any other possible drug-related problems". 1

The Central Drugs Standard Control Organisation (CDSCO), Directorate General of Health Services under the aegis of Ministry of Health and Family Welfare, Government of India in collaboration with the Indian Pharmacopeia Commission (IPC), Ghaziabad is conducting a nation-wide Pharmacovigilance Program of India (PvPI) for protecting the health of the patient by assuring drug safety. The programme is coordinated by the IPC as a National Coordinating Centre (NCC). The 
mission of PvPI is to safeguard the health of the Indian population by ensuring that the benefits of use of medicine outweigh the risks associated with its use. The vision of PvPI is to improve patient safety and thereby reducing the risk associated with use of medicine. ${ }^{2}$

Our AMC (Adverse drug Reaction Monitoring Centre) is designated under PvPI and is working for the safety and welfare of patients by early detection, reporting and monitoring of ADR in hospital setup and by providing its prompt and appropriate management.

This is a retrospective study done to analyse the ADR reported at our AMC to know the type and pattern of ADR reported, demographic profile of patients, organ system involved, causative drugs, severity, outcome, management and causality assessment, in view of improving health safety of patients.

\section{METHODS}

At our AMC data was collected from various clinical departments and ADR reporting was done on the prescribed "Suspected Adverse Drug Reaction Reporting Form" provided by IPC. ${ }^{3}$ Causality Assessment was performed using WHO Uppsala Monitoring Centre (UMC) Causality Assessment Criteria. The reports were then uploaded in vigiflow software and send to NCC, IPC Ghaziabad, which further sends the reports after analysing to Uppsala Monitoring Centre, Sweden for maintaining ADR database, further analysis and signal detection.

The 60 suspected ADR reports received from various clinical departments from March 2015 to April 2016 were analysed retrospectively for the type and pattern of ADR reported, demographic profile of patients, organ system involved, causative drugs, and severity, outcome, management and causality assessment.
This study was done after maintaining strict confidentiality about the particulars of involved patients. Data analysis was done using descriptive statistical analysis.

\section{RESULTS}

The age group in the range of 41-50 years with mean age 45.6 years $(n=15.25 \%)$, was most commonly involved in ADRs followed by $>60$ years age group $(n=12,20 \%)$ and 50-60 years age group $(n=10,16.66 \%)$.

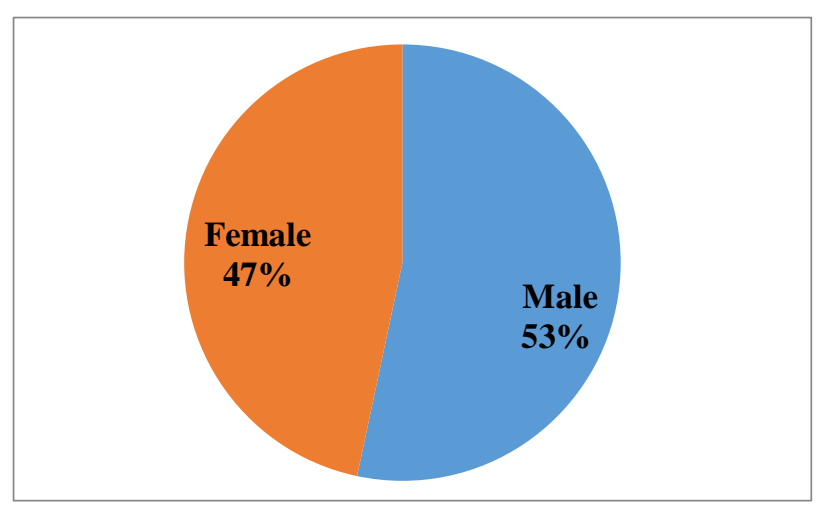

Figure 1: Gender distribution of patients.

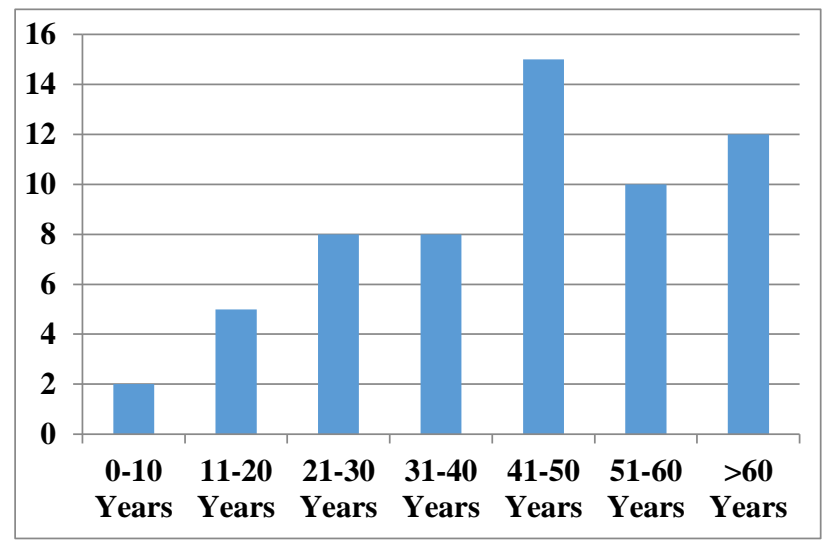

Figure 2: Age distribution of patients.

Table 1: Organ systems involved in ADRs.

\begin{tabular}{|lll|}
\hline Organ systems involved & Types of ADRs & n (\%) \\
$\begin{array}{l}\text { Cutaneous ADRs } \\
\text { (Skin and appendages involvement) }\end{array}$ & $\begin{array}{l}\text { Skin rashes(13), Itching(8), Skin hyperpigmentation(2), Stevens } \\
\text { Johnson's Syndrome(2), Alopecia(1), Injection site pain(1) }\end{array}$ & $27(45 \%)$ \\
\hline $\begin{array}{l}\text { Generalised ADRs } \\
\text { (Whole body involvement) }\end{array}$ & $\begin{array}{l}\text { Fever (3), Anaphylaxis(2), Propofol infusion syndrome (1), } \\
\text { Phenytoin toxicity(1), Sweating(1), Chills(1) }\end{array}$ & $9(15 \%)$ \\
\hline $\begin{array}{l}\text { Gastrointestinal ADRs } \\
\text { (GIT involvement) }\end{array}$ & $\begin{array}{l}\text { Diarrhoea/ Loose stools(4), Vomiting(1), Constipation(1), Mouth } \\
\text { ulcer(1), Abdominal pain(1), Mucositis(1) }\end{array}$ & $9(15 \%)$ \\
\hline Respiratory system ADRs & $\begin{array}{l}\text { Respiratory distress/ Breathlessness(4), Suffocation(1),Chest } \\
\text { congestion (1), Chest pain(1) }\end{array}$ & $7(11.66 \%)$ \\
\hline Central Nervous System ADRs & Numbness(2), Headache(1) & $3(5 \%)$ \\
\hline Cardiovascular System ADRs & Hypotension(1), Hypertension(1) & $2(3.33 \%)$ \\
\hline Renal System ADRs & Hypokalaemia(1) & $1(1.66 \%)$ \\
\hline $\begin{array}{l}\text { Haematological System ADRs } \\
\text { Blood) }\end{array}$ & Anemia(1) & $1(1.66 \%)$ \\
\hline Dental & Periodontitis(1) & $1(1.66 \%)$ \\
\hline
\end{tabular}


The gender distribution showed slight male preponderance $(n=32,53 \%)$ as compared to females $(n=28,47 \%)$ (Figure 1 and 2).
Skin reactions $(n=27,45 \%)$ like rashes and itching were the most common ADRs reported followed by gastrointestinal $(n=9,15 \%)$ and generalised reactions $(n=9,15 \%)$ like diarrhoea and fever respectively (Table 1).

Table 2: Causative drug classes involved in suspected ADR.

\begin{tabular}{|ll|}
\hline Drug class & $\mathrm{n}(\%)$ \\
\hline $\begin{array}{l}\text { Antimicrobial agents- Ciprofloxacin(3), Levofloxacin(3), Ofloxacin+ornidazole(2), Norfloxacin(2), } \\
\text { Ceftriaxone(2), Cefoparazone(2), Pipercillin+Tazobactum(2), Cefuroxime(1), Amikacin(1), } \\
\text { Clindamycin(1), Doxycycline(1), Amoxicillin(1), Colistin(1) }\end{array}$ & $22(33.66 \%)$ \\
\hline $\begin{array}{l}\text { Antiepileptic drugs- Oxcarbazepine(3), Phenytoin(2), Pregabalin(2), Acetazolamide(1), } \\
\text { Levetiracetam(1), Clobazam(1) }\end{array}$ & $10(16.66 \%)$ \\
\hline $\begin{array}{l}\text { Chemotherapeutic agents- Pacitaxel(2),5-fluorouracil(2), Doxorubicin + Cyclophosphamide } \\
\text { (1),Oxaliplatin }\end{array}$ & $6(10 \%)$ \\
\hline Nutritional supplements-Albumin(Human)(3), Aminoplasmalhepa 10\%(1) & $4(6.66 \%)$ \\
\hline Electrolyte supplements-Ringer lactate fluid(2), Potassium Chloride(1) & $3(5 \%)$ \\
\hline Antifungal agents-Amphotericin B(3) & $3(5 \%)$ \\
\hline Angiotensin Receptor blocker-Losartan(1) & $1(1.66 \%)$ \\
\hline Anaesthetic agent-Propofol(1) & $1(1.66 \%)$ \\
\hline Anti-tubercular drug- Isoniazid(1) & $1(1.66 \%)$ \\
\hline Anti-fibrinolytic agent-Tranaxemic Acid(1) & $1(1.66 \%)$ \\
\hline NSAID-Paracetamol(1) & $1(1.66 \%)$ \\
\hline Opioid analgesic-Tramadol(1) & $1(1.66 \%)$ \\
\hline Anti-retroviral therapy-Efaviranz+Lamivudine+Tenofovir(1) & $1(1.66 \%)$ \\
\hline Immunomodulator-Thalidomide(1) & $1(1.66 \%)$ \\
\hline Sympathomimetic agent-Noradrenaline(1) & $1(1.66 \%)$ \\
\hline Antimalarial agent-Artesunate+Pyrimethmine+Sulphadoxine(1) & $1(1.66 \%)$ \\
\hline Corticosteroid-Clobetasol(1) & $1(1.66 \%)$ \\
\hline Contrast Media & $1(1.66 \%)$ \\
\hline
\end{tabular}

Table 3: Seriousness, outcome and management of ADRs.

\begin{tabular}{|c|c|c|c|c|c|}
\hline Seriousness & & Outcome & & Management & \\
\hline \multirow{2}{*}{ Serious } & \multirow{2}{*}{$19(83 \%)$} & Recovered & $53(88.33 \%)$ & Drug withdrawn & $55(91.66 \%)$ \\
\hline & & Non recovered & $3(5 \%)$ & Drug continued with same dose & $4(6.66 \%)$ \\
\hline \multirow{2}{*}{ Non serious } & \multirow{2}{*}{$41(17 \%)$} & Fatal(Death) & $3(5 \%)$ & \multirow{2}{*}{ Drug dose reduced } & \multirow{2}{*}{$1(1.66 \%)$} \\
\hline & & Unknown & $1(1.66 \%)$ & & \\
\hline
\end{tabular}

According to Rawlins and Thompson classification, which classifies ADR as type A (Augmented/ Predictable) and type B (Bizarre/Unpredictable), 85\% (n=51) ADRs belonged to type B category while only $15 \%(n=9)$ were type A ADRs (Figure 4$).{ }^{4}$

Majority of ADRs (83\%, $\mathrm{n}=41)$ were non-serious while $17 \%$ (19) were of serious nature. Most of the patients i.e., $88.33 \%$ recovered; of these $61.66 \%$ (37) recovered with medical help after stopping the suspected drug and $26.66 \%$ (16) recovered without medical help just by stopping the suspected drug, 5\% (3) cases did not recover at all while $5 \%$ (3) cases were fatal. The outcome of $1.66 \%$ (1) cases was unknown. In $91.66 \%$ (55) cases, the suspected drug was stopped, in $6.66 \%$ (4) cases the suspected drug was continued with same dose while $1.66 \%$ (1) cases the dose of suspected drug was reduced.

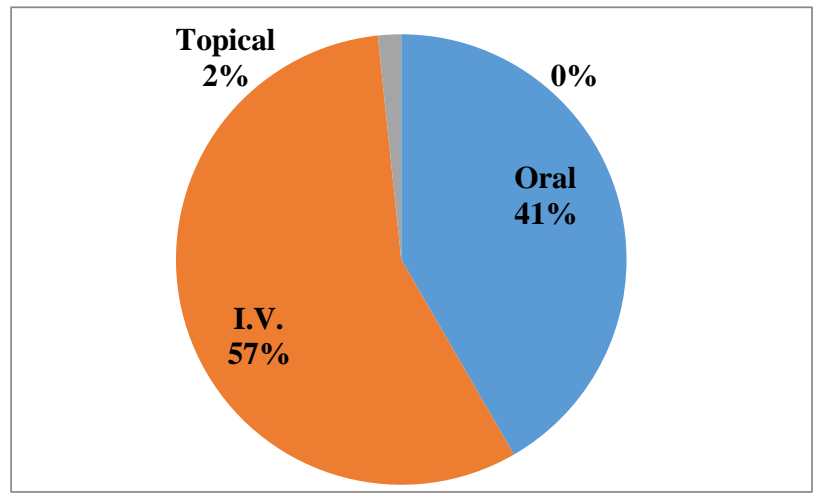

Figure 3: Route of drug administration.

The most common drugs causative of ADR were antimicrobial agents $22(33.66 \%)$ followed by 
antiepileptic $(\mathrm{n}=10,16.66 \%)$ and chemotherapeutic agents $6(10 \%)$ (Table 2). Parenteral route (IV) was most commonly involved route $(n=34,57 \%)$ followed by oral route $(\mathrm{n}=25,41 \%)$. Topical route was least involved in ADR, 1 (2\%) (Table 2, Figure 3).

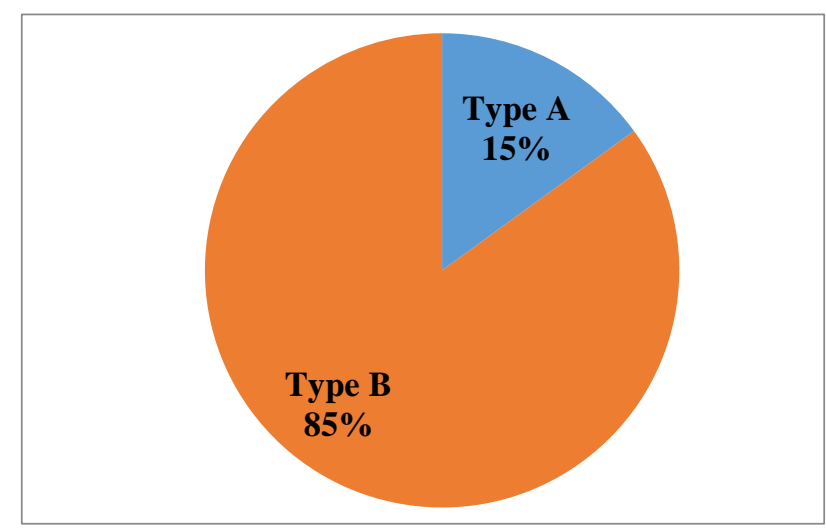

Figure 4: Type of ADR.

According to modified Hartwig and Siegel scale, 61.66\% (37) ADRs belonged to moderate category, 23.33\% (14) ADRs were of mild category while $15 \%$ (9) ADRs were severe (Figure 5). ${ }^{5}$

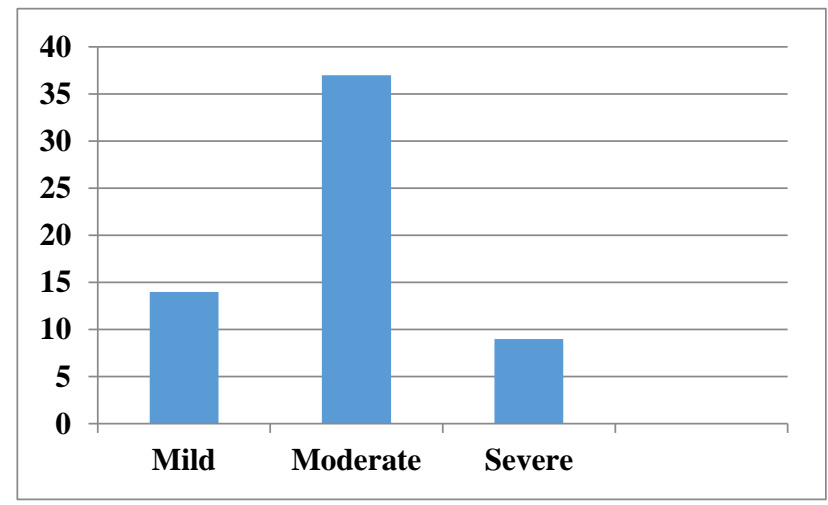

Figure 5: Severity of ADR.

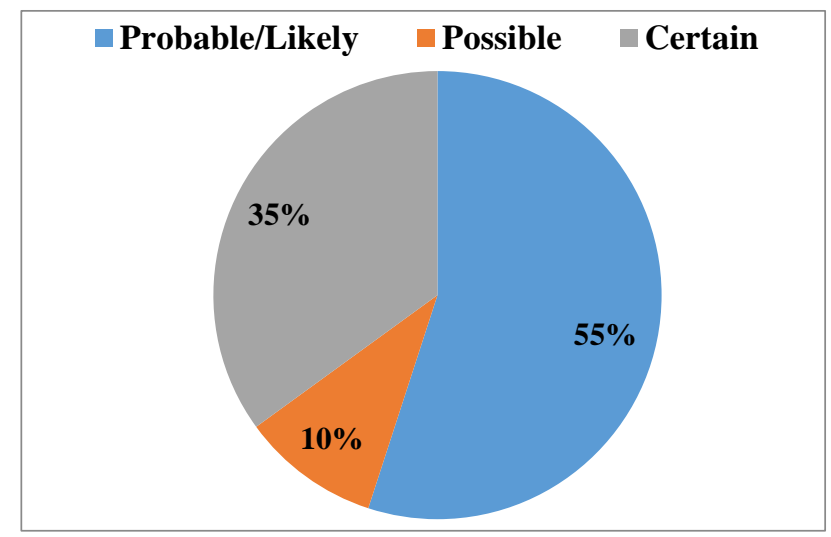

Figure 6: Causality assessment.

According to WHO-UMC causality assessment criteria, maximum ADRs 55\% (33) were probable with the suspected drug, 35\% (21) were possible while $10 \%$ (6) were certain (Figure 6). ${ }^{6}$

\section{DISCUSSION}

ADRs are a major cause of mortality and morbidity in hospitals in present scenario. There is under-reporting of these reactions due to lack of awareness and communication which has to be taken care of, to prevent the iatrogenic diseases in hospital setup. This retrospective analytic study was done to identify the ADRs occurring in our hospital, their pattern, type, demographic profile of patients, causative drugs, organ systems involved, severity and causality assessment.

A total of 60 ADR was reported over a period of 14 months, which showed slight male preponderance. Several other studies have also found similar results. ${ }^{7-9}$ However, some studies showed female preponderance. ${ }^{10,11}$ Thereby concluding that influence of gender is just an incidental finding and it does not affects number of ADR reported. The age group most commonly affected was 41-50 years (25\%) with mean age 45.6 years, this was similar in other studies also. ${ }^{12,13}$ The age of the patients will depend upon the type of patients the hospital is catering for; since our Institution was providing care only to adult patients at that time as we were not running pediatric services, adult patients were reported.

The organ system most commonly affected by ADRs was skin $(45 \%)$ followed by generalised body reactions and gastrointestinal reactions with both having an equal frequency of $15 \%$ and respiratory system reactions with $11.66 \%$ frequency. A similar trend has been reported in other studies. ${ }^{14,15}$ The common ADRs shown by patients were rashes, itching, respiratory distress, diarrhoea and fever. This pattern has been reported in other study also. ${ }^{16}$ Parenteral route (IV) was most commonly involved in ADR $(57 \%)$ followed by oral route $(41 \%)$. Topical route is least involved in ADR (2\%). According to Rawlins and Thompson classification, $85 \%$ ADRs belonged to type B category while only $15 \%$ were type A.

While a vast majority of ADRs (83\%) wasnon-serious, only $17 \%$ were serious. Again, majority $(88.33 \%)$ of the patients recovered, 5\% did not recover at all while $5 \%$ cases were fatal. The outcome of $1.66 \%$ cases was unknown. In $91.66 \%$ patients the suspected drug was stopped, in $6.66 \%$ patients the suspected drug was continued with same dose while in $1.66 \%$ patients the dose of suspected drug was reduced.

According to modified Hartwig and Siegel scale, $61.66 \%$ ADRs belonged to moderate category, 23.33\% ADRs were of mild category while $15 \%$ ADRs were severe. These patterns of ADRs were consistent with other studies. ${ }^{17,18}$

According to WHO-UMC causality assessment criteria, $55 \%$ ADRs were probable with the suspected drug, 35\% were possible while $10 \%$ were certain. These results were 
similar to a study but different from the results observed in another study. ${ }^{19,20}$

The first limitation of the study is that it is of relatively short duration. This is due to the fact that our center was newly created. Secondly, there was under-reporting due to lack of awareness and communication which is a wellknown limitation of spontaneous reporting of ADR. Moreover, the Technical Associate provided by the PvPI was removed from our center that was main reason for under reporting. Lastly, the result may not be generalizable to entire population as this data is limited to our institution only but this data will definitely contribute to the pattern of ADRs reported in tertiary care hospitals. Lack of patient follow up was another limitation.

\section{CONCLUSION}

Our study concluded that ADR occurred more commonly in population with mean age 45.6 years with slight male preponderance, but these may be incidental findings. Most commonly reported ADRs were cutaneous reactions like rashes and itching and antimicrobial agents were most commonly involved drugs causing ADR. Parenteral (IV) route was the most commonly involved route of drug administration. Most of the reactions were non-serious, moderate category and the patients recovered with medical help in most cases. Only 3 cases were fatal. According to WHO-UMC causality assessment most reactions were probable/likely with the suspected drugs.

Though this study had few limitations, it strongly suggests that the need of the hour is to create awareness of hospital based ADR reporting and monitoring system and to develop and promote culture of ADR reporting through a proper communication channel among health care professionals for ensuring patient safety.

Funding: No funding sources

Conflict of interest: None declared

Ethical approval: The study was approved by the Institutional Ethics Committee

\section{REFERENCES}

1. Glossary of pharmacovigilance terms. Available at: https://www.who-umc.org/global-

pharmacovigilance/global-

pharmacovigilance/glossary/. Assessed 3 September 2017.

2. PvPI reaches out to rural masses. Available at: http://www.ipc.gov.in/PvPI/newsletter3/newsletter3.h tml\#page/4. Assessed 3 September 2017.

3. ADR reporting form. Available at: http://www.ipc.gov.in/PvPI/adr.html. Assessed 3 September 2017.

4. Rawlins MD, Thompson JW. Mechanisms of adverse drug reactions. In: Davies DM, editor. Textbook of adverse drug reactions. Oxford: Oxford University Press; 1991:18-45.
5. Hartwig SC, Siegel J, Schneider PJ. Preventability and severity assessment in reporting adverse drug reactions. Am J Hosp Pharm. 1992;49(9):2229-32.

6. The use of the WHO-UMC system for standardized case causality assessment. Available at: https://www.who-umc.org/media/2768/standardisedcase-causality-assessment. Accessed 3 September 2017.

7. Lobo MG, Pinheiro SM, Castro JG, Momenté VG, Pranchevicius MC. Adverse drug reaction monitoring: Support for pharmacovigilance at a tertiary care hospital in Northern Brazil. BMC Pharmacol Toxicol. 2013;14:5.

8. Dutta SB, Beg MA, Bawa S, Anjoom M, Varma A, Singh NK. A retrospective analysis of adverse drug reactions in a tertiary care teaching hospital at Dehradun, Uttarakhand. Int J Basic Clin Pharmacol. 2015;4(1):121-4.

9. Subbanna PK, Chandy SJ. The role of active surveillance in improving the hospital adverse drug event reporting. Indian J Pharmacol. 2006;38:363-4.

10. Miller MA. Gender-based differences in the toxicity of pharmaceuticals - the food and drug Administration's perspective. Int J Toxicol. 2001;20(3):149-52.

11. Ramesh M, Pandit J, Parthasarathi G. Adverse drug reactions in a south Indian hospital - their severity and cost involved. Pharmacoepidemiol Drug Saf. 2003;12(8):687-92.

12. Kharb P, Mittal N, Gupta MC. An evaluation of adverse drug reactions monitoring at a pharmacovigilance unit under pharmacovigilance programme of India in a tertiary care hospital of Haryana. Int J Basic Clin Pharmacol. 2015;4:556-60.

13. Patel KJ, Kedia MS, Bajpai D, Mehta SS, Kshirsagar NA, Gogtay NJ. Evaluation of the prevalence and economic burden of adverse drug reactions presenting to the medical emergency department of a tertiary referral centre: a prospective study. BMC Clin Pharmacol. 2007;7:8.

14. Patidar D, Rajput MS, Nirmal NP, Savitri W. Implementation and evaluation of adverse drug reaction monitoring system in a tertiary care teaching hospital in Mumbai, India. Interdiscip Toxicol. 2013;6(1):41-6.

15. Jose J. Rao PG. Pattern of Adverse Drug Reactions Notified By Spontaneous Reporting In An Indian Tertiary Care Teaching Hospital. Pharmacol Res. 2006;54(3):226-33.

16. Caranasos GJ, Stewart RB, Cluff LE. Drug-induced illness leading to hospitalization. JAMA. 1974;228(6):713-7.

17. Shareef SM, Naidu CDM, Raikar SR, Rao YV, Devika U. Development, implementation and analysis of adverse drug reaction monitoring system in a rural tertiary care teaching hospital in Narketpally, Telangana. Int J Basic Clin Pharmacol. 2015;4:75760.

18. Vijayakumar TM, Dhanaraju MD. Description of adverse drug reactions in a multi-speciality teaching hospital. Int J Integr Med. 2013;1(26):1-6. 
19. Suh DC, Woodall BS, Shin SK, Hermes-De Santis ER. Clinical and economic impact of adverse drug reactions in hospitalized patients. Ann Pharmacother. 2000;34(12):1373-9.

20. Murphy BM, Frigo LC. Development, implementation and results of a successful multidisciplinary adverse drug reaction reporting program in a university teaching hospital. Hosp Pharm. 1993;28(12):1199204,1240 .

Cite this article as: Sen M, Singh A, Misra M. Retrospective analysis of adverse drug reactions reported at ADR monitoring centre under PvPI in a tertiary care hospital. Int J Basic Clin Pharmacol 2018;7:303-8. 